\title{
Analysis of E.U. Rapid Alert System (RASFF) Notifications for Aflatoxins in Exported U.S. Food and Feed Products for 2010-2019
}

\author{
Ahmad Alshannaq and Jae-Hyuk Yu *iD \\ Department of Bacteriology, University of Wisconsin-Madison, 1550 Linden Drive, Madison, WI 53706, USA; \\ alshannaq@wisc.edu \\ * Correspondence: jyu1@wisc.edu
}

check for

updates

Citation: Alshannaq, A.; Yu, J.-H. Analysis of E.U. Rapid Alert System (RASFF) Notifications for Aflatoxins in Exported U.S. Food and Feed Products for 2010-2019. Toxins 2021, 13, 90. https://doi.org/10.3390/ toxins 13020090

Received: 3 January 2021

Accepted: 22 January 2021

Published: 26 January 2021

Publisher's Note: MDPI stays neutral with regard to jurisdictional claims in published maps and institutional affiliations.

Copyright: (c) 2021 by the authors. Licensee MDPI, Basel, Switzerland. This article is an open access article distributed under the terms and conditions of the Creative Commons Attribution (CC BY) license (https:// creativecommons.org/licenses/by/ $4.0 /)$.

\begin{abstract}
The most common, toxic, and carcinogenic mycotoxins found in human food and animal feed are the aflatoxins (AFs). The United States is a leading exporter of various nuts, with a marketing value of $\$ 9.1$ billion in 2019; the European Union countries are the major importers of U.S. nuts. In the past few years, border rejections and notifications for U.S. tree nuts and peanuts exported to the E.U. countries have increased due to AF contamination. In this work, we analyzed notifications from the "Rapid Alert System for Food and Feed (RASFF)" on U.S. food and feed products contaminated with mycotoxins, primarily AFs, for the 10-year period 2010-2019. Almost 95\% of U.S. mycotoxin RASFF notifications were reported for foods and only $5 \%$ for feeds. We found that $98.9 \%$ of the U.S. food notifications on mycotoxins were due to the AF contamination in almond, peanut, and pistachio nuts. Over half of these notifications (57.9\%) were due to total AF levels greater than the FDA action level in food of $20 \mathrm{ng} \mathrm{g}^{-1}$. The Netherlands issued $27 \%$ of the AF notifications for U.S. nuts. Border rejection was reported for more than $78 \%$ of AF notifications in U.S. nuts. All U.S. feed notifications on mycotoxins occurred due to the AF contamination. Our research contributes to better understanding the main reasons behind RASFF mycotoxins notifications of U.S. food and feed products destined to E.U. countries. Furthermore, we speculate possible causes of this problem and provide a potential solution that could minimize the number of notifications for U.S. agricultural export market.
\end{abstract}

Keywords: RASFF notifications; mycotoxin; aflatoxin contamination; United States nuts; pistachios; border rejection

Key Contribution: In this study, we highlight the occurrence of aflatoxins in the U.S. food and feed products destined to E.U countries, reported by RASFF notifications system for the last decade. This study provides a basis to investigate the root problems associated with aflatoxin contamination in U.S. tree nuts and may help to assess risk factors.

\section{Introduction}

Mycotoxins are unavoidable and unpredictable toxic fungal secondary metabolites produced by three major genera of soil-borne molds: Aspergilli, Fusarium, and Penicillium [1,2]. The most common, toxic, and carcinogenic mycotoxin found in human food and animal feed are the aflatoxins (AFs), especially aflatoxin B1 (AFB1) [3-5]. AFs have been reported to be present in a wide variety of crops, including corn, wheat, soy, rice, cottonseed, tree nuts, oilseeds, herbs, and spices. Animal byproducts such as milk, meat, and egg can also be at risk of AF contamination [1,6-9]. Moreover, AF contamination is one of the key foodborne risks that is greatly influenced by climate conditions. High temperatures, humid weather, and drought stress are favorable conditions for dissemination of and infestation by the primary AF-producing fungus Aspergillus flavus [10,11]. Therefore, the ongoing global warming is expected to elevate the levels of AF contamination, especially in fields at the pre-harvest stage [11-15]. 
The United States is continuing to be a major producer and exporter of tree nuts such as almonds, pistachios, walnuts, pecans, and hazelnuts, and is one of the leading exporters of groundnuts (peanuts) worldwide Tables 1 and 2 [16]. In 2019, the market value of the U.S. tree nut and peanut exports to the world was $\$ 9.1$ billion and $\$ 675$ million, respectively. The European Union countries are the largest market for U.S. tree nuts, importing more than a third of all exported U.S. tree nuts, and they represent the third greatest market for exported U.S. peanuts [17-20]. Unfortunately, all these edible nuts are prone to fungal infestation and contamination with mycotoxins, especially AFs, that hamper the flow of the nuts across borders. Worryingly, increasing numbers of incidents where U.S. tree nuts exported to the E.U. countries have been rejected at the border because of AF contamination have occurred in the past decade.

Table 1. Marketing value of top 10 U.S. agricultural export for 2015-2019.

\begin{tabular}{|c|c|c|c|c|c|c|}
\hline & Products & 2015 & 2016 & 2017 & 2018 & 2019 \\
\hline 1 & Soybeans & 18,862 & 22,839 & 21,456 & 17,063 & 18,660 \\
\hline 2 & Tree Nuts & 8441 & 7902 & 8479 & 8514 & 9075 \\
\hline 3 & Beef and Beef Products & 6311 & 6360 & 7263 & 8360 & 8090 \\
\hline 4 & Corn & 8271 & 9879 & 9112 & 12,467 & 7617 \\
\hline 5 & Pork and Pork products & 5567 & 5936 & 6485 & 6403 & 6952 \\
\hline 6 & Prepared Food & 5849 & 6188 & 5938 & 6245 & 6682 \\
\hline 7 & Wheat & 5628 & 5346 & 6058 & 5389 & 6214 \\
\hline 8 & Cotton & 3902 & 3967 & 5845 & 6557 & 6153 \\
\hline 9 & Dairy Products & 5240 & 4698 & 5377 & 5498 & 5931 \\
\hline \multirow[t]{3}{*}{10} & Soybean Meal & 4781 & 4073 & 3881 & 5079 & 4405 \\
\hline & All Others & 60,206 & 57,558 & 58,266 & 58,021 & 56,880 \\
\hline & Total exported & 135,073 & 136,762 & 140,177 & 141,614 & 138,678 \\
\hline
\end{tabular}

Values in millions of dollars. Ethanol is not counted as an agricultural good in the USDA definition of agriculture Source: United States Agricultural Export Yearbook, USDA, 2019.

Table 2. Values of top 10 export markets for U.S. Tree Nuts for 2015-2019.

\begin{tabular}{clccccc}
\hline \multicolumn{1}{c}{ Products } & $\mathbf{2 0 1 5}$ & $\mathbf{2 0 1 6}$ & $\mathbf{2 0 1 7}$ & $\mathbf{2 0 1 8}$ & $\mathbf{2 0 1 9}$ \\
\hline $\mathbf{1}$ & European Union & $\mathbf{2 9 7 7}$ & $\mathbf{2 5 8 5}$ & $\mathbf{2 7 0 7}$ & $\mathbf{2 7 6 9}$ & $\mathbf{3 1 1 4}$ \\
2 & India & 606 & 521 & 738 & 663 & 823 \\
3 & Canada & 686 & 598 & 643 & 696 & 696 \\
4 & Hong Kong & 846 & 1156 & 1251 & 1052 & 692 \\
5 & China & 208 & 182 & 243 & 328 & 606 \\
6 & United Arab Emirates & 430 & 310 & 301 & 304 & 439 \\
7 & Japan & 480 & 374 & 398 & 433 & 416 \\
8 & Mexico & 269 & 253 & 256 & 371 & 344 \\
9 & Turkey & 300 & 365 & 308 & 279 & 341 \\
10 & South Korea & 354 & 296 & 305 & 290 & 290 \\
& All Others & 1285 & 1261 & 1329 & 1331 & 1314 \\
& Total Exported & 8441 & 7901 & 8479 & 8516 & 9075 \\
\hline
\end{tabular}

Values in millions of dollars. Source: United States Agricultural Export Yearbook, USDA, 2019.

Mycotoxin contamination results in more notifications than any other hazard in the Rapid Alert System for Food and Feed (RASFF), and the foremost toxin that has been associated with the notifications is AFs, especially in the nuts and nut products [1,21-24]. RASFF was established in 1979 by the E.U. countries to allow swift exchange of information on hazards in food and feed (chemical, biological, physical, and allergens) among the E.U. countries. All food and feedstuff imported into E.U. are checked by the competent authorities of the Member States, and when risks to public health are detected during these checks, information is disseminated through the RASFF to all E.U. Member States and to the exporting countries [24-26]. In recent years, certain audits have been conducted in U.S. by the European Commission/Directorate-General for Health and Food Safety in response 
to continuing high number of RASFF notifications for AF contamination in tree nuts and peanuts imported from the U.S $[1,27,28]$.

Despite tremendous efforts to control fungal toxin contamination of food and feed products, U.S. tree nut and peanut consignments destined to the E.U. countries are often being rejected due to AF levels exceeding not only the E.U. maximum limit but even the FDA action level. This serious matter prompted us to analyze RASFF notifications for the occurrence of mycotoxins in food and feed products of U.S. origin exported to the E.U. countries during the period of 2010 to 2019. We mostly focused on food samples because they accounted for $95.7 \%$ of all food and feed notifications, and we considered AF contamination as the target for this study as it represents $98.9 \%$ of mycotoxin notifications. In this report, we examined the levels of AF contamination in food products of U.S. origin, notification years, the types of rejection, the countries issuing the most notifications, and the product category that is frequently contaminated with AFs. We aim to provide readyto-access data on mycotoxin contamination of food and feed products originating from the U.S. and exported to the E.U. countries. Moreover, the numbers of RASSS mycotoxin notifications issued for food products from other countries exported to E.U. countries were compared to those issued for U.S. food products. Along with other tracing tools, this study will help to explore the root problems contributing to AF contamination in U.S. tree nuts and may help to assess risk factors associated with the problem.

\section{Results}

2.1. RASFF Mycotoxin Notifications for U.S.-Originated Food Products and the Affected Food Category

Between 2010 and 2019, 442 mycotoxin notifications were reported for food products originated in the U.S. Of these, $98.9 \%$ (437) notifications were reported for AFs. Most of these notifications (97.7\%) were associated with nuts (almonds, pistachios and peanuts). Of these, 22\% (99) were reported for almonds, 42\% (187) for pistachios, and 34\% (151) for peanuts (Figure 1A). As reported by the RASFF portal, the products for which almond notifications occurred included 57\% "almond" $(n=56), 20 \%$ "shelled almond" $(n=20), 8 \%$ "almond in shell" $(n=8), 2 \%$ "salted and roasted almond" $(n=2), 6 \%$ "almond kernels" $(n=6), 5 \%$ "whole almond with skin" $(n=5)$, and $1 \%$ for "peeled almond" $(n=1)$. Pistachio notifications were distributed as follows: $25 \%$ "pistachio in shell" $(n=67), 37.7 \%$ "pistachio nut" $(n=71), 7.9 \%$ "shelled pistachio" $(n=15), 7.4 \%$ "salted and roasted pistachio" $(n=12)$, $6.3 \%$ "pistachio kernels and chopped" $(n=12)$, and $4.7 \%$ "raw pistachio" $(n=9)$. For peanut (groundnut) notifications, notifications occurred in the following categories: $50 \%$ "peanut" (groundnut; $n=69), 22.7 \%$ "shelled peanut" $(n=31), 7.4 \%$ "blanched peanut" $(n=15), 7.3 \%$ "peanut kernels" $(n=10), 6.6 \%$ "peanut in shell" $(n=9)$, and $1.4 \%$ "salted and roasted peanut" $(n=2)$ (Figure $1 \mathrm{~B})$.

Very few notifications were reported by RASFF for apricot kernels $(n=1)$, peanut butter $(n=4)$, shelled walnuts $(n=1)$, and pecan nuts $(n=4)$ during 2010 to 2019 . Only five notifications $(1.13 \%)$ were reported for other mycotoxins in U.S. originated food during this time period. Two notifications were for the ochratoxin A contamination in ground corn for tortillas (37.32 $\mathrm{ng} \mathrm{g}^{-1}$ ) and spaghetti $\left(7200 \mathrm{ng} \mathrm{g}^{-1}\right)$. Three notifications were reported for deoxynivalenol in wheat $\left(n=2 ; 1676\right.$ and $\left.3138 \mathrm{ng} \mathrm{g}^{-1}\right)$ and maize $\left(n=1 ; 2688 \mathrm{ng} \mathrm{g}^{-1}\right)$. 


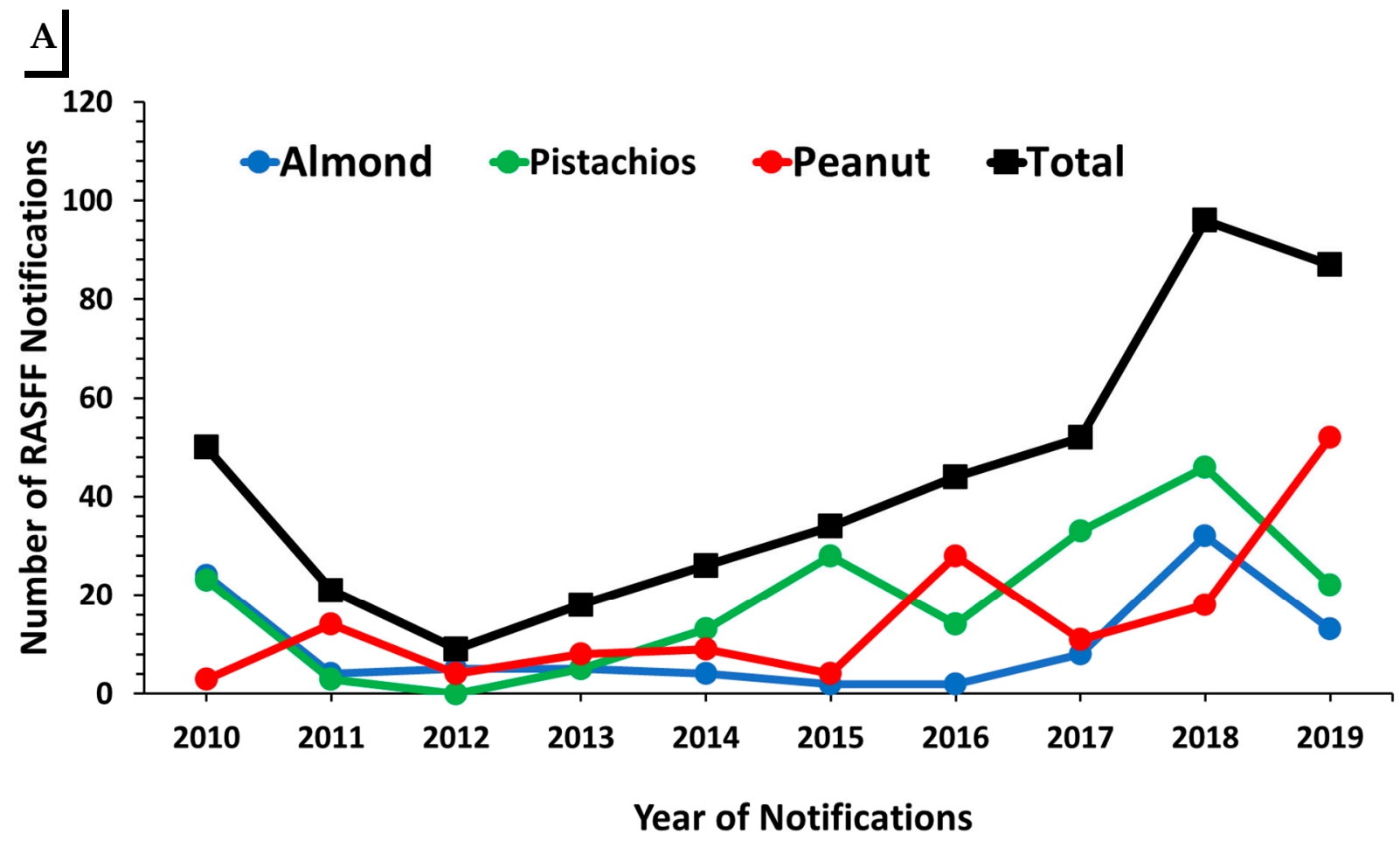

B

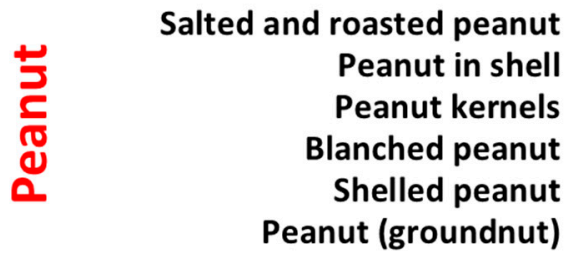

$\begin{array}{rr}\text { Raw pistachios } \\ .0 & \text { Pistachios kernels and chopped } \\ \text { Roatsed and salted pistachios } \\ \text { Shelled pistachios } \\ \text { Pistachios in shell } \\ \text { Pistachios nut }\end{array}$

Peeled Almond

동 Salted and roasted almond
Whole almond with skin
Almond kernels
Almond in shell
Shelled almond Almond
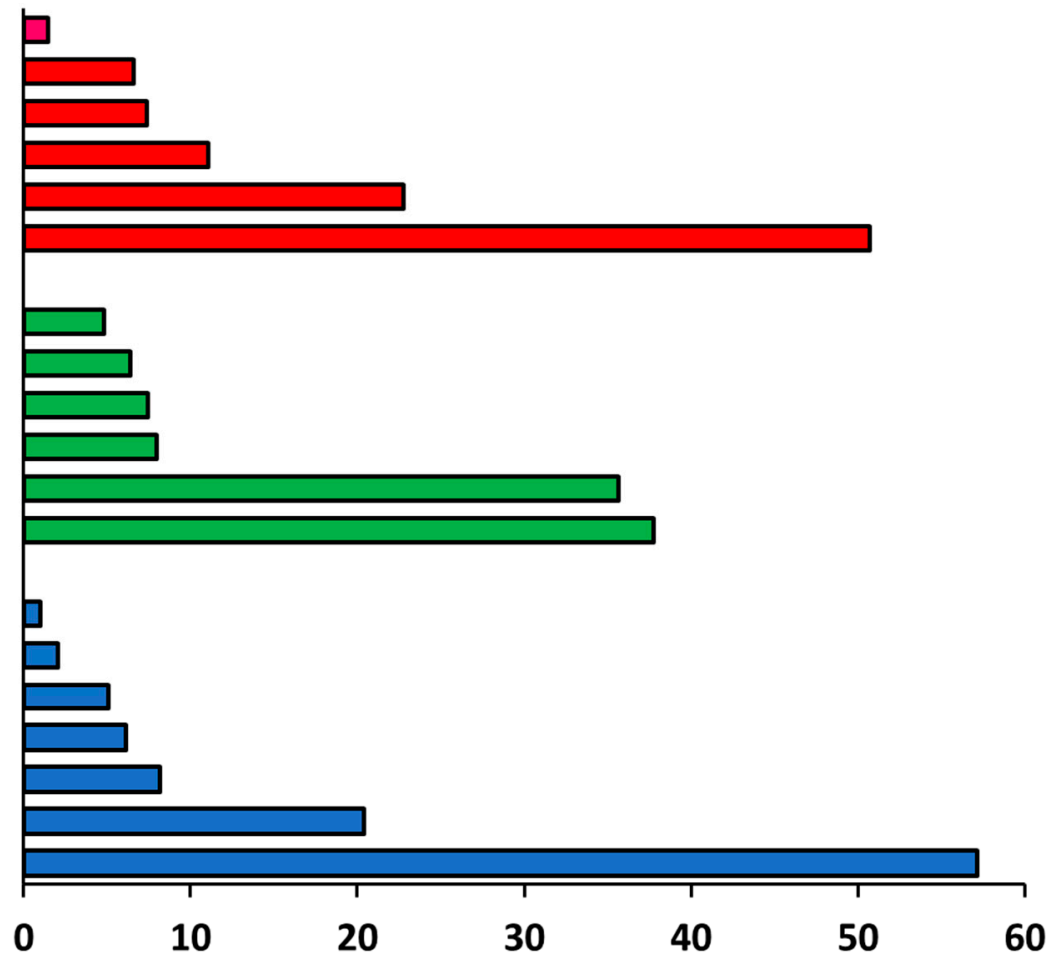

$\%$ of RASFF notifications

Figure 1. RASFF aflatoxin notifications in nuts of U.S. origin. (A) Number of RASFF notifications for aflatoxin in U.S. reported as food products during 2010-2019. Total number of notifications is shown in black. (B) Distribution of RASSF notifications for nuts of U.S. origin reported during 2010-2019 as food products. Almonds (blue), pistachios (green) and peanuts (red). 


\subsection{Levels of AF Contamination in the U.S. Nuts as Specified in RASFF Notifications}

The percentage of U.S. nuts containing AFs from 2010 to 2019 notified by RASFF is illustrated in Figure 2. We allocated the RASFF notifications by the levels of AF contamination in U.S. nuts into three groups: $>4$ to $\leq 10 \mathrm{ng} \mathrm{g}^{-1}$ as group one, $>10$ to $<20 \mathrm{ng} \mathrm{g}^{-1}$ as group two, and $\geq 20 \mathrm{ng} \mathrm{g}^{-1}$ (FDA action level) as group three. Based on this classification, we found that $19 \%$ of notifications fell into group one $(n=81), 23 \%$ into group two $(n=98)$, and $57.9 \%$ of the notifications into group three $(n=247)$.

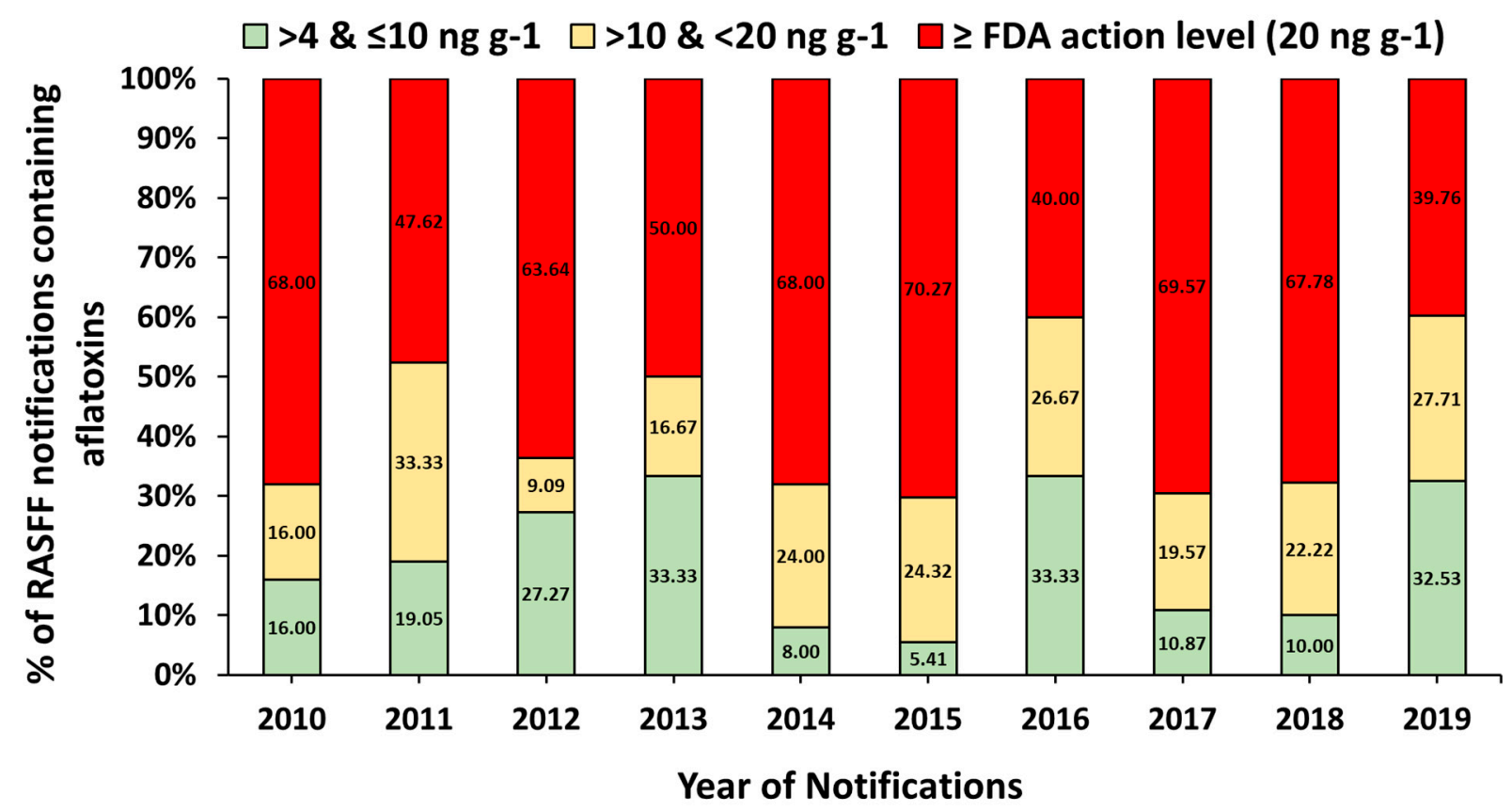

Figure 2. Percentage of U.S. nuts (as foods) containing aflatoxin for 2010 to 2019 as notified by RASFF.

\subsection{Notification Types and Notifying Countries}

Figure 3A shows the numbers of the RASFF AF notifications based on the type of notifications for 2010 to 2019. The RASFF notifications for AF in the U.S. originated nuts were classified as border rejection (78\%), alert (5.8\%), and information for attention and follow-up $(15.8 \%)$. The top five major notifying countries were the Netherlands with $27 \%$ of notifications $(n=126)$, Spain with $12.33 \%$ of notifications $(n=57)$, Italy and the United Kingdom with $11.4 \%$ of notifications each ( $n=53$ each), and Germany with $10.3 \%$ of notifications $(n=48)$. Other E.U. countries reported $27 \%$ of RASFF notifications (Figure 3B). In 2019, the top five major notifying countries were the Netherlands with $39 \%$ of notifications, the United Kingdom with $16 \%$ of notifications, Italy with $13 \%$ of notifications, Spain with $11 \%$ of notifications and Germany with $7.0 \%$ of notifications. Other E.U. countries reported $14 \%$ of RASFF notifications (Figure 3C). 

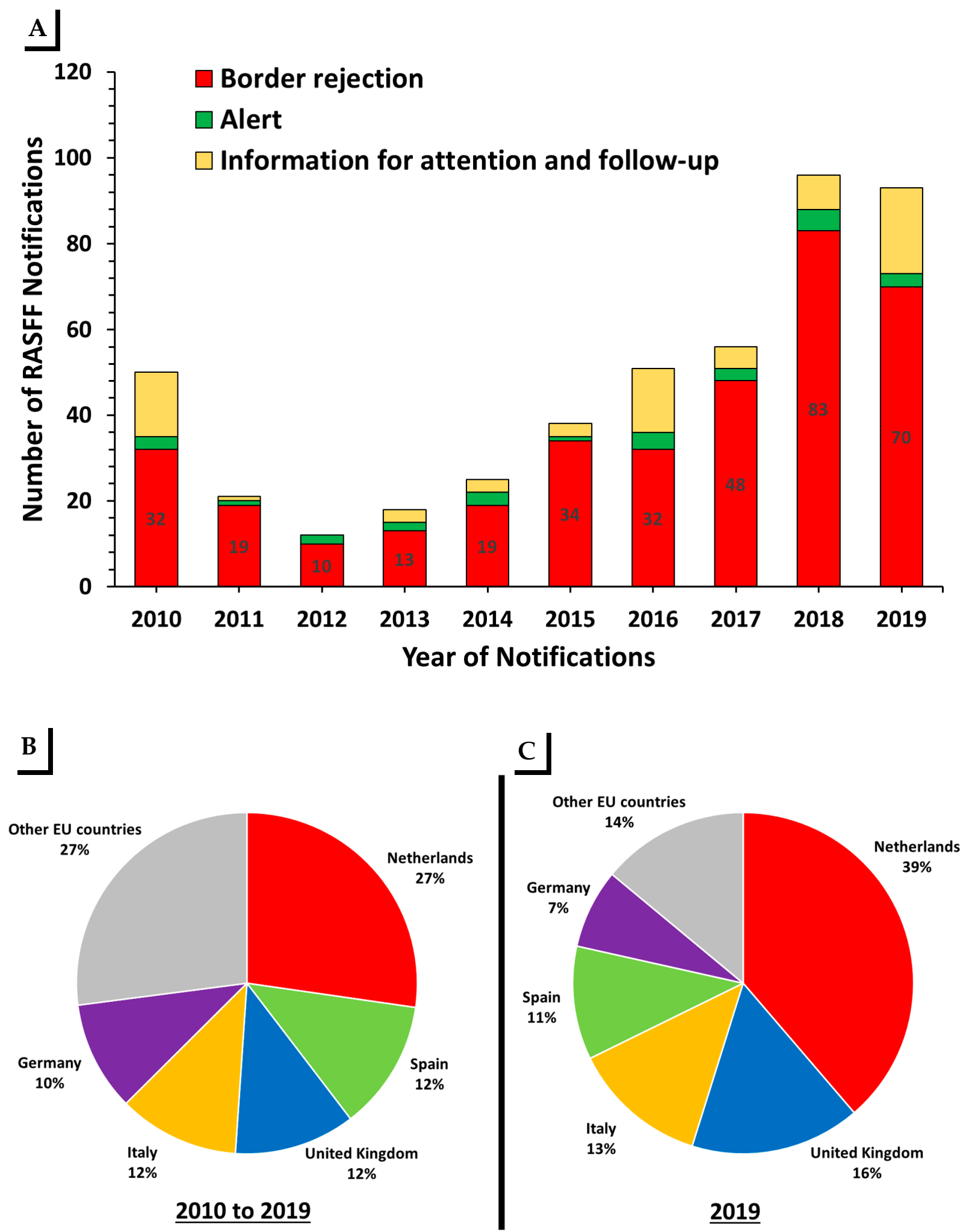

Figure 3. RASFF Notifications on U.S. food products and the top five notifying countries. (A) Number of RASFF notifications for aflatoxin contamination in food products based on type of notification for 2010 to 2019. (B,C) Percentage of RASFF notifications for aflatoxin in U.S. nuts (as food products) according to notifying country from 2010 to 2019 (B) and in the year 2019 (C). 


\subsection{RASFF Mycotoxin Notifications on the U.S. Originated Feed Products and the Affected Feed Category}

Twenty mycotoxin notifications for feed products of U.S. origin were reported by RASFF during 2010 to 2019. All of these notifications were reported for AF contamination of groundnuts for birdfeed and wildlife. Levels of total AF contamination ranged from $28 \mathrm{ng} \mathrm{g}^{-1}$ to $220 \mathrm{ng} \mathrm{g}^{-1}$. Ten notifications reported total AF levels in the range of $>20$ and $\leq 50 \mathrm{ng} \mathrm{g}^{-1}$, seven notifications fell in the range of $>50$ and $\leq 100 \mathrm{ng} \mathrm{g}^{-1}$, and three notifications reported AFs levels of more than $100 \mathrm{ng} \mathrm{g}^{-1}$. About $80 \%$ of these notifications were classified as border rejections and the other $20 \%$ were classified as information for attention.

\subsection{RASFF Mycotoxin Notifications for Global Food and Feed Products for 2010 to 2019}

RASFF reported 5045 and 439 notifications for mycotoxin contamination in food and feed products, respectively, exported to E.U. countries from around the world during the years 2010 to 2019. Amongst food notifications, $89 \%(n=4487)$ of notifications for mycotoxin contamination were attributed to AF contamination. The second most reported mycotoxin was ochratoxin A with $10 \%(n=507)$ of the RASFF notifications. Deoxynivalenol, fumonisins, zearalenone and patulin were reported in $1.01 \%(n=51), 0.71 \%(n=36), 0.23 \%$ $(n=36)$ and $0.09 \%(n=5)$ RASFF notifications, respectively (Figure 4$)$.

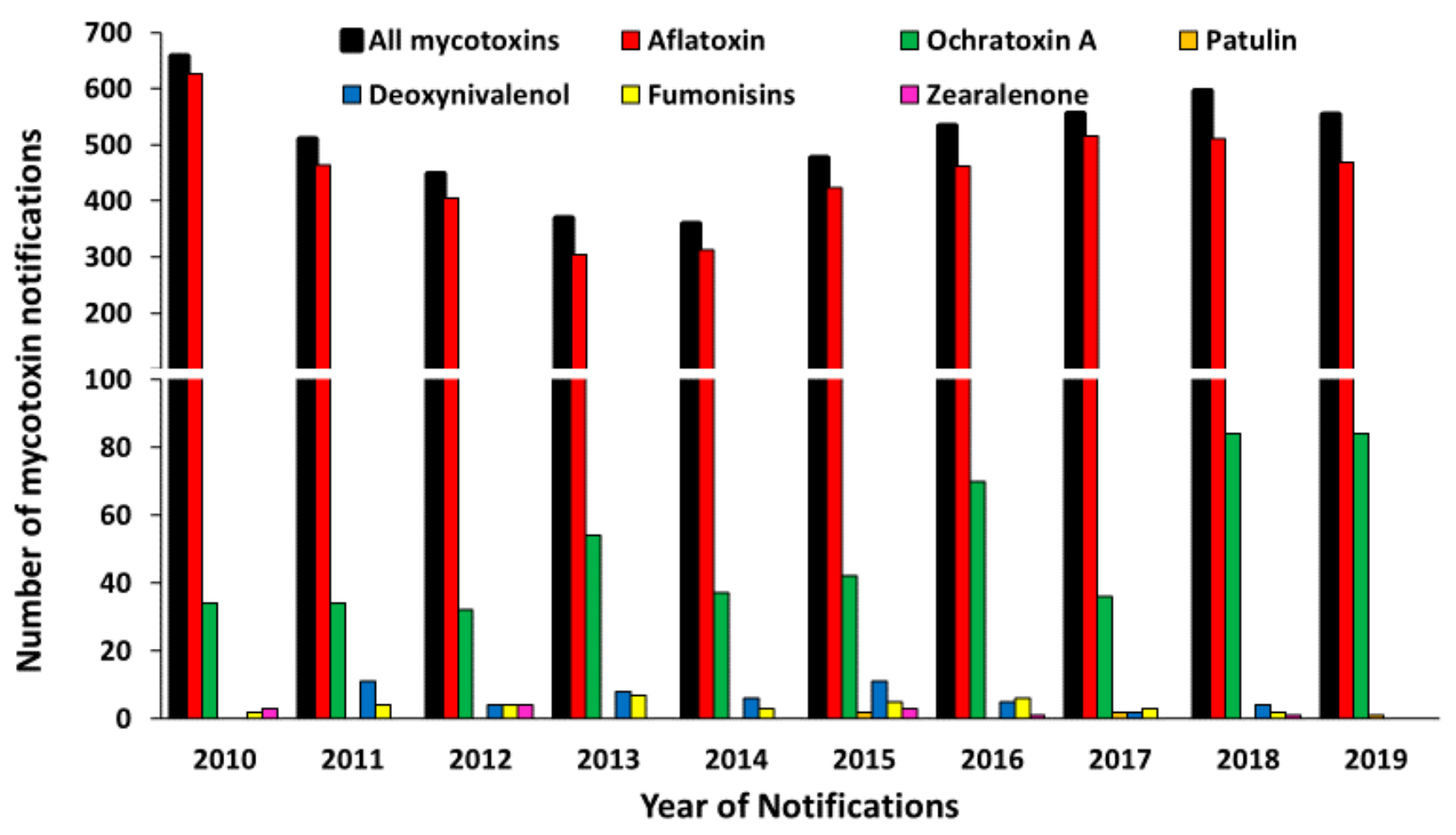

Figure 4. Total number of RASFF notifications for mycotoxins per year over ten years in food products from all countries over 2010 to 2019 .

The top 10 countries linked to $80 \%$ of RASFF mycotoxin notifications on food products were Turkey $(32.7 \%)$, China (15.1\%), India (12.2\%), U.S. (10.7\%), Iran (9.5\%), Argentina $(8.0 \%)$, Egypt $(4.8 \%)$, Brazil $(2.6 \%)$, Pakistan $(1.7 \%)$, Nigeria $(1.5 \%)$, and Ghana $(1.3 \%)$ (Figure 5A). However, during 2010 to 2019, mycotoxin notifications were reported for more than 97 countries including the E.U. countries (Figure 5B). 
A

$\square$ Turkey

$\square$ China

$\square$ India

United states

Iran

Argentina

Egypt

Brazil

Pakistan

Nigeria

Ghana

Others

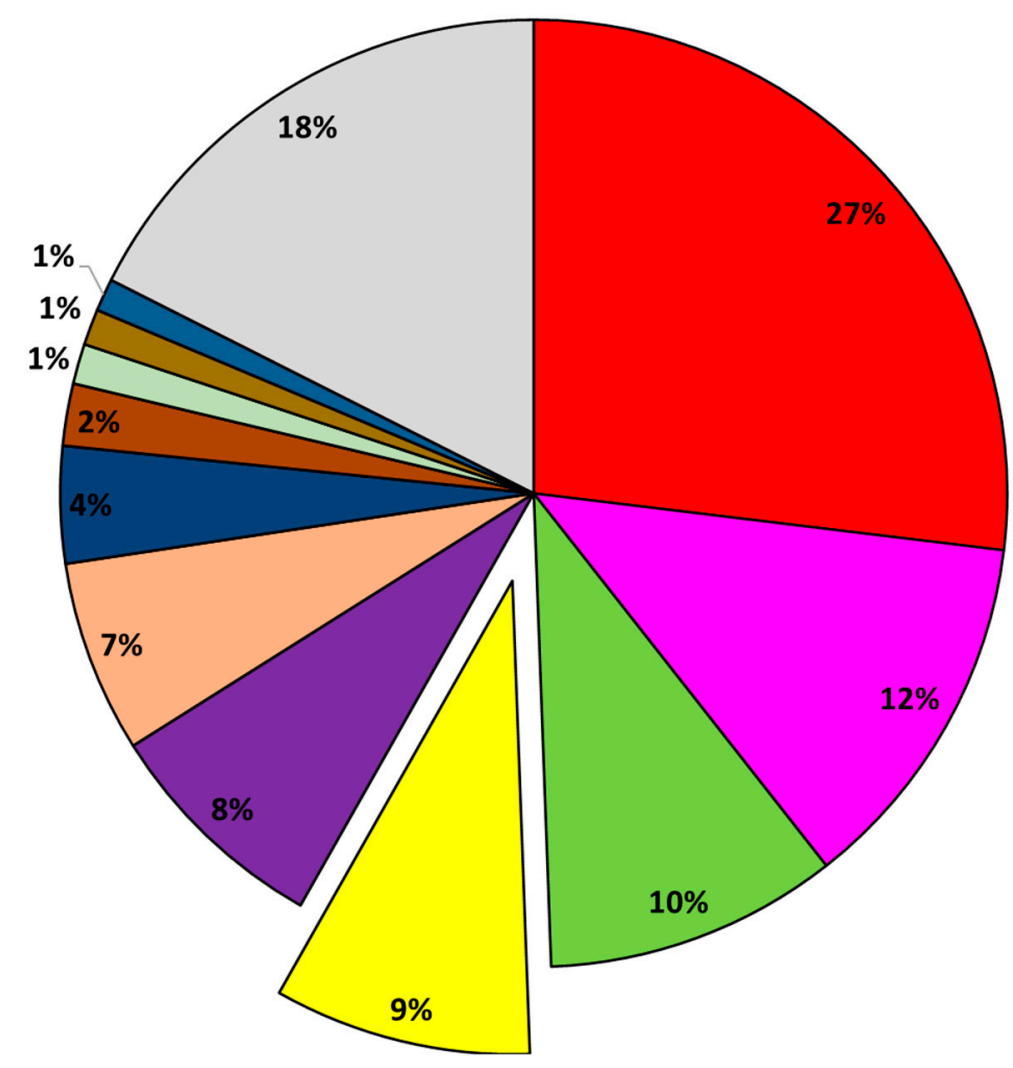

B

Number of aflatoxin notifications $\quad 1 \quad 1325$

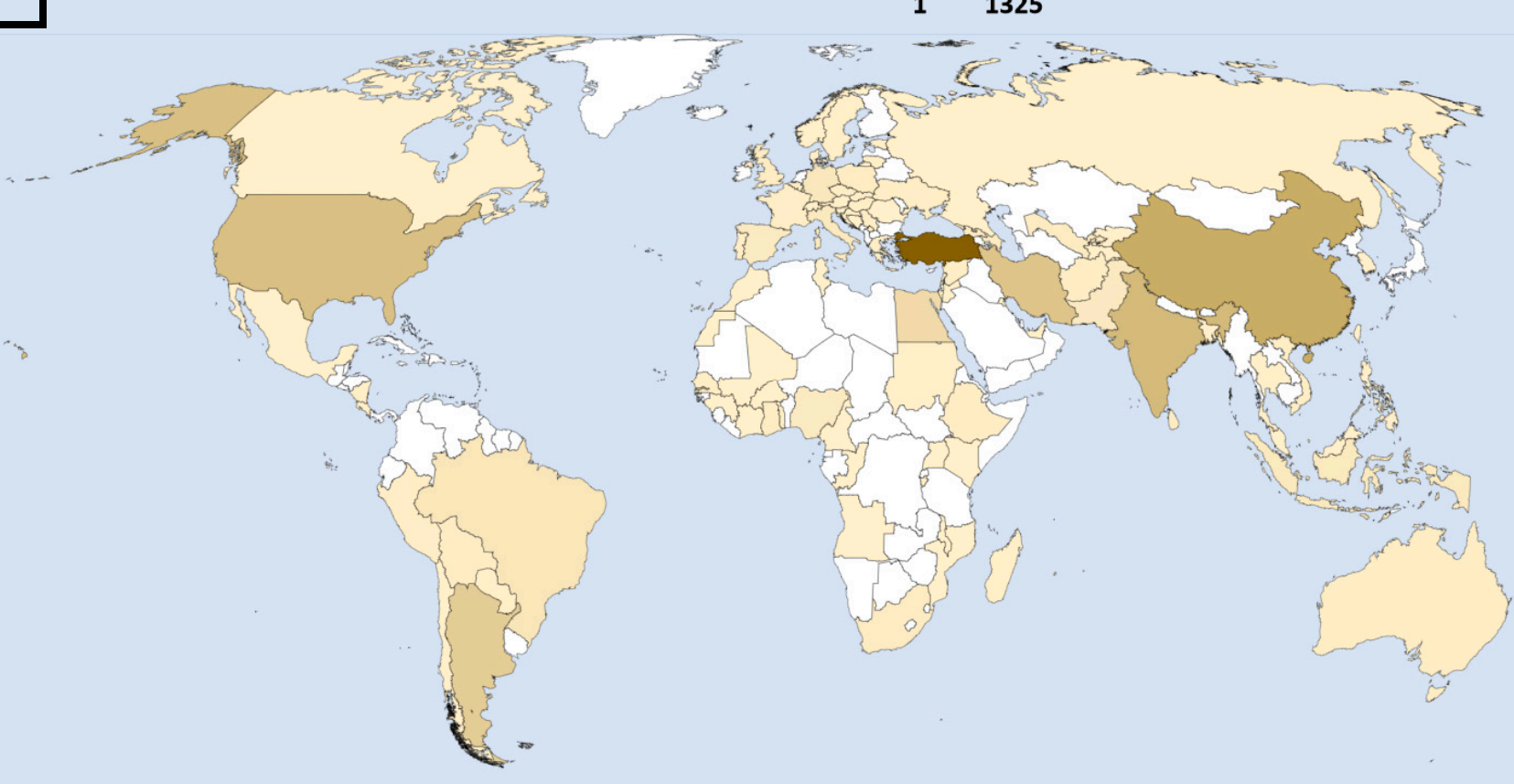

Figure 5. Source of RASFF notifications for mycotoxins in food products from all countries. (A) Percentage of RASFF notifications for mycotoxins in food products according to the country of origin. (B) Number of RASFF notifications for mycotoxins in food products according to the country of origin during 2010 to 2019. 
Regarding feed products, AF contamination was reported in 98.6\% $(n=433)$ of the RASFF notifications. Three notifications were reported for zearalenone, two for T-2 and HT-2 toxins and one notification was recorded for deoxynivalenol. The most frequently contaminated feed were groundnuts $(n=342)$, maize $(n=51)$, sunflower seeds $(n=16)$, cotton seeds $(n=4)$, rice bran $(n=4)$, sorghum $(n=3)$, compound feed $(n=3)$, and others $(n=16)$.

\section{Discussion}

\subsection{Summary of the Analysis of the RASFF Notifications}

To the best of our knowledge, there are no publications or available reports which assess RASFF notifications for AF contamination of the U.S. nuts. In this work, we primarily analyzed RASFF AF notifications for U.S. food products exported to E.U. countries during the last ten years (2010 to 2019). We found that $98.9 \%$ of the notifications were reported for AF contamination of nuts (almonds, peanuts, and pistachios). The most frequent notifications were reported for pistachios (42\%) followed by peanuts (34\%) and almonds $(22 \%)$. All kinds of nuts such as shelled nuts, nuts in the shell, kernels nut, or roasted and salted nuts were reported to have AFs in the RASFF notifications, with different prevalences and levels of contamination. More than half of these notifications (57.9\%) reported total AF levels greater than the U.S. FDA action level for food $\left(20 \mathrm{ng} \mathrm{g}^{-1}\right)$. About $19 \%$ of notifications reported AF levels in the range of $>4$ to $\leq 10 \mathrm{ng} \mathrm{g}^{-1}$, and $23 \%$ reported AF levels between $>10$ and $\leq 20 \mathrm{ng} \mathrm{g}^{-1}$. The Netherlands issued more of these notifications than any other E.U. country, with issuing more than $27 \%$ of AF notifications for U.S. nuts. The numbers of border rejections for U.S. nuts exported to E.U. countries, as cited in RASFF notifications, have been increased due to AF contaminations in the last few years. The number of such notifications was 87 in 2019, 96 in 2018, 52 and 2017, 44 in 2016, and 34 in 2015.

Border rejections constituted more than $78 \%$ of notifications for AF contamination in nuts that originated in the U.S. Only $1.13 \%$ of U.S. nuts were reported to be contaminated with other mycotoxins. Ochratoxin A contamination was reported in two notifications in ground corn and spaghetti. Deoxynivalenol was reported in three notifications associated with wheat and maize. No notifications were reported for patulin, fumonisins, zearalenone, and patulin.

We analyzed the RASFF notifications for mycotoxins in feed products of U.S. origin. We identified 20 relevant notifications. Interestingly, all these notifications reported AF contamination in groundnuts for birdfeed and wildlife. The levels of AF contaminations were $28 \mathrm{ng} \mathrm{g}^{-1}$ to $220 \mathrm{ng} \mathrm{g}^{-1}$. About $80 \%$ of these notifications were classified as border rejections, with the other $20 \%$ classified as information for attention. The country issuing the most notifications for mycotoxins in feed products of U.S. origin was the United Kingdom followed by the Netherlands.

For the years 2010 to 2019, RASFF reported 5045 and 439 notifications on mycotoxin contaminations in food and feed products, respectively, exported to E.U. countries from all countries around the world. The U.S. is the fourth top country linked to the notifications, behind Turkey, China, and India. Among the notifications for food products from all countries, $89 \%(n=4487)$ of the reported notifications attributed to AF contamination. The second most reported mycotoxin in food products was ochratoxin A, which was responsible for $10 \%(n=507)$ of the RASFF notifications. Deoxynivalenol, fumonisins, zearalenone, and patulin were reported in less than $2 \%$ of notifications.

Regarding the feed products from all countries, AF contamination was reported in $98.4 \%$ of the RASFF notifications. Of these, $77.9 \%$ of the contaminated feed products were groundnuts and $11.6 \%$ were maize. Sunflower seeds, cottonseeds, rice bran, sorghum, and compound feed were also reported to be contaminated with AFs. 


\subsection{Problem Characterization}

Due to frequent RASFF notifications for U.S. nuts destined to E.U. countries in recent years, some assessments have been conducted by the European Commission/DirectorateGeneral for Health and Food Safety in the U.S. for pistachios and peanuts [27,28]. Overall, highly limited official U.S. control measures to tackle AF contaminations were noted, according to the findings of the most recent audit on peanuts (7-15 October 2019). In addition, sampling for AFs and analysis and validation of data for peanuts intended for export to the E.U. has not been performed to meet the $100 \%$ of the requirements of Regulation (EC) No. 401/2006 [27]. Another audit on U.S. pistachios that was conducted 5-12 September 2017, found that there were no official controls or requirements applicable to pistachios intended for export to E.U. In addition, there were no legal requirements applicable to these exports to ensure those sampling methods, analyses or reporting procedures fulfilled Regulation (EC) No 401/2006. Furthermore, samples rejected by RASFF due to AF contamination were not adequately followed up in the U.S. system to investigate possible root causes or to implement preventive measures [28].

While the USDA has implemented an instrument called AF certification for peanuts and tree nuts and has also adopted pre-export controls and check on AFs in U.S. nuts, most of these programs are voluntary. Most companies exporting to E.U. have signed memorandum of understanding to comply with these programs. No official controls are performed to verify compliance with this program, and there is no official supervision of consignments destined for the E.U. relating to AF contamination $[27,28]$.

Another possible explanation for the large number of RASFF notifications on U.S. nuts is the gap between the FDA action level and the E.U. maximum level of contamination. The U.S. FDA has established an action level of $20 \mathrm{ng} \mathrm{g}^{-1}$ for total AFs (B1, B2, G1 and G2) for foods, peanut, and peanut products, and pistachio nuts [1,29]. European maximum levels for AF contamination of groundnuts, tree nuts, and processed nut products for direct human consumption are $2.0 \mathrm{ng} \mathrm{g}^{-1}$ for AFB1 and $4.0 \mathrm{ng} \mathrm{g}^{-1}$ for total AFs. If the nuts are subject to sorting or other physical treatment before consumption or will be used as an ingredient in foodstuffs, the limits for AFB1 and total AFs are $8.0 \mathrm{ng} \mathrm{g}^{-1}$ and $15 \mathrm{ng} \mathrm{g}^{-1}$ for groundnuts and $5 \mathrm{ng} \mathrm{g}^{-1}$ and $10 \mathrm{ng} \mathrm{g}^{-1}$ for tree nuts, respectively [30].

The lack of a surveillance program and a regular monitoring system to detect AF contamination and levels of contamination represent significant drawbacks that the U.S. is facing in the fight against AFs. No studies for the occurrence and levels of AFs in the U.S. nuts for 2010 2019 have been published. Regular monitoring and testing are insufficiently employed at the level of individual states. The results of the states' monitoring and surveillance packages could serve as a useful tool if the levels of AFs are elevated in a geographical area, alerting growers to the need for more attention and testing.

\section{Conclusions and Recommendations}

Almost 95\% of U.S. mycotoxin RASFF notifications were reported for foods and only $5 \%$ for feeds. The number of E.U. RASFF notifications and border rejections of U.S. nuts, mainly pistachios, almonds, and peanuts, due to contamination with AFs have increased over last ten years (2010 to 2019). More than $50 \%$ of notifications were due to AF levels not only exceeding the E.U. maximum limits but also the U.S. FDA's action level. Pistachios were the nut type responsible for the most notifications over the last ten years. Border rejections constituted more than $78 \%$ of RASFF notifications for AF contamination in U.S. nuts destined to E.U countries.

RASFF reported 5045 and 439 notifications for mycotoxin contamination in food and feed products, respectively, exported to E.U. countries from around the world during the years 2010 to 2019 . About $89 \%$ of food and $98.6 \%$ of feed notifications for mycotoxin contamination were attributed to AF contamination.

The growing numbers of reports on the health benefits of eating nuts will likely lead to increased consumption of these products. In addition, the food industry using large numbers of tree nuts to manufacture pastries, sweets, ice cream, and confectionary 
products. As U.S. continues to be the largest supplier of tree nuts to the globe, especially to E.U. countries, it is therefore of great importance to keep U.S. nuts sheltered from AF contamination by implementing a mandatory and enforceable legal framework for official export control procedures concerning AFs in nuts.

To avoid escalating numbers of E.U. RASSF notifications, U.S. sampling, method validation, and results and reporting should comply with the E.U. requirements of Regulation (EC) No 401/2006. Importantly, comprehensive surveillance data on the occurrence and levels of AFs in almonds, pistachios, and peanuts are urgently needed to assess the current and ongoing conditions of the problem. The rejected shipments of the nuts exported from U.S. to E.U. countries due to AF contaminations should be adequately followed up on in order to identify possible root causes and/or to implement preventive measures.

\section{Material and Methods}

Data were obtained from the RASFF portal (https://webgate.ec.europa.eu/rasffwindow / portal/? event=SearchForm\&cleanSearch=1). Search criteria for the RASFF mycotoxins notifications in the U.S food and feed products over ten years (2010 to 2019) were as follows: Type "food and feed", Hazard category "mycotoxins", notified between "01/01/2010" and "31/12/2019", product flagged as "origin", product country "United States (US)". Search criteria for the worldwide RASFF notifications in food products over ten years ((2010 to 2019) were: Type "food", Hazard category "mycotoxins", notified between "01/01/2010" and "31/12/2019", product flagged as "origin", product country "not specified". The extracted data were exported from the RASFF portal directly to Microsoft Excel 2010 (Microsoft 365 MSO) to generate descriptive statistics. Each single notification list contained data in the following order: product category, date, reference, product type, notification type, notification basis, notified by, countries concerned, subject, action taken, distribution status, and risk decision. When more than one originating country was mentioned, or two countries (one for raw product origin and the other for processing and packaging), we considered the country of origin of the raw food.

Levels of AF contamination were extracted from the "subject" category into the Excel column. Usually, the RASFF portal presents the results on AFB1 and total AFs (B1, B2, G1, G2). In this report, we considered the total AFs because the FDA action level is set for total AFs. Therefore, AF concentrations in this report represent the summation of four AFs (B1, B2, G1, G2).

There are three major types of RASFF notifications: alert, information, and border rejection. Alert notifications typically are delivered through RASFF when the hazard is detected in food and feed that are already present in the E.U. market and a rapid action is required to protect the public. Information notifications are used when a hazard is detected in food or feed placed in the market of one E.U. country but has not reached other E.U. members' markets. In this case, the risk does not require rapid actions. Regulation (E.U.) No 16/2011 defines two sub-types of information notifications: 'information notifications for follow-up' and "information notifications for attention". Border rejections are concerned with food and feed consignments that have been rejected at the external borders of the E.U. due to the presence of hazard in food and feed $[21,24,31]$.

Author Contributions: Designed the research work, A.A. and J.-H.Y.; Performed the research and drafted the paper, A.A.; Supervised the research work and revised the draft, J.-H.Y. All authors have read and agreed to the published version of the manuscript.

Funding: This research received no external funding.

Institutional Review Board Statement: Not applicable.

Informed Consent Statement: Not applicable.

Data Availability Statement: The data presented in this study are openly available in the European Commission RASFF portal database (https: / / webgate.ec.europa.eu/rasff-window/portal). 
Acknowledgments: We thank Wendy Bedale of the Food Research Institute at the University of Wisconsin-Madison for critically reviewing the manuscript. Support for this research was provided by Food Research Institute and the University of Wisconsin-Madison Office of the Vice Chancellor for Research and Graduate Education (OVCRGE) with funding from the Wisconsin Alumni Research Foundation.

Conflicts of Interest: The authors declare that the research was conducted in the absence of any commercial or financial relationships that could be construed as a potential conflict of interest.

\section{References}

1. Alshannaq, A.; Yu, J.-H. Occurrence, Toxicity, and Analysis of Major Mycotoxins in Food. Int. J. Environ. Res Public Health 2017, 14, 632. [CrossRef] [PubMed]

2. Bennett, J.W.; Klich, M. Mycotoxins. Clin. Microbiol. Rev. 2003, 16, 497-516. [CrossRef] [PubMed]

3. EFSA Panel on Contaminants in the Food Chain; Schrenk, D.; Bignami, M.; Bodin, L.; Chipman, J.K.; Del Mazo, J.; Grasl-Kraupp, B.; Hogstrand, C.; Hoogenboom, L.R.; Leblanc, J.-C.; et al. Risk assessment of aflatoxins in food. EFSA J. 2020, 18 , e06040. [CrossRef] [PubMed]

4. Ostry, V.; Malir, F.; Toman, J.; Grosse, Y. Mycotoxins as human carcinogens-the IARC Monographs classification. Mycotoxin. Res. 2017, 33, 65-73. [CrossRef] [PubMed]

5. Alshannaq, A.F.; Yu, J.-H. A Liquid Chromatographic Method for Rapid and Sensitive Analysis of Aflatoxins in Laboratory Fungal Cultures. Toxins 2020, 12, 93. [CrossRef] [PubMed]

6. Mahato, D.K.; Lee, K.E.; Kamle, M.; Devi, S.; Dewangan, K.N.; Kumar, P.; Kang, S.G. Aflatoxins in Food and Feed: An Overview on Prevalence, Detection and Control Strategies. Front. Microbiol. 2019, 10. [CrossRef]

7. Ozbey, F.; Kabak, B. Natural co-occurrence of aflatoxins and ochratoxin A in spices. Food Control 2012, 28, 354-361. [CrossRef]

8. Cano-Sancho, G.; Sanchis, V.; Marín, S.; Ramos, A.J. Occurrence and exposure assessment of aflatoxins in Catalonia (Spain). Food Chem. Toxicol. Int. J. Publ. Br. Ind. Biol. Res. Assoc. 2013, 51, 188-193. [CrossRef]

9. Serraino, A.; Bonilauri, P.; Kerekes, K.; Farkas, Z.; Giacometti, F.; Canever, A.; Zambrini, A.V.; Ambrus, Á. Occurrence of Aflatoxin M1 in Raw Milk Marketed in Italy: Exposure Assessment and Risk Characterization. Front. Microbiol. 2019, 10. [CrossRef]

10. Valente, S.; Meloni, G.R.; Prencipe, S.; Spigolon, N.; Somenzi, M.; Fontana, M.; Gullino, M.L.; Spadaro, D. Effect of Drying Temperatures and Exposure Times on Aspergillus flavus Growth and Aflatoxin Production on Artificially Inoculated Hazelnuts. J. Food Protect. 2020, 83, 1241-1247. [CrossRef]

11. Mitchell, N.J.; Bowers, E.; Hurburgh, C.; Wu, F. Potential economic losses to the US corn industry from aflatoxin contamination. Food Addit. Contam. Part A Chem. Anal. Control Expo. Risk Assess. 2016, 33, 540-550. [CrossRef] [PubMed]

12. Cotty, P.J.; Jaime-Garcia, R. Influences of climate on aflatoxin producing fungi and aflatoxin contamination. Int. J. Food Microbiol. 2007, 119, 109-115. [CrossRef] [PubMed]

13. Medina, A.; Rodriguez, A.; Magan, N. Effect of climate change on Aspergillus flavus and aflatoxin B1 production. Front Microbiol 2014, 5, 348. [CrossRef] [PubMed]

14. Paterson, R.R.M.; Venâncio, A.; Lima, N.; Guilloux-Bénatier, M.; Rousseaux, S. Predominant mycotoxins, mycotoxigenic fungi and climate change related to wine. Food Res. Int. 2018, 103, 478-491. [CrossRef]

15. Van der Fels-Klerx, H.J.; Vermeulen, L.C.; Gavai, A.K.; Liu, C. Climate change impacts on aflatoxin B1 in maize and aflatoxin M1 in milk: A case study of maize grown in Eastern Europe and imported to the Netherlands. PLoS ONE 2019, 14, e0218956. [CrossRef]

16. United States Department of Agriculture, Foreign Agricultural Service. United States Agricultural Export Yearbook; USDA Foreign Agricultural Service: Washington, DC, USA, 2019.

17. USDA, United States Department of Agriculture, Foreign Agriculture Service. Tree Nuts: World Markets and Trade, Pistachios; USDA Foreign Agricultural Service: Washington, DC, USA, 2020.

18. USDA, United States Department of Agriculture, Foreign Agriculture Service. Tree Nuts Annual; USDA Foreign Agricultural Service: Washington, DC, USA, 2019.

19. Ortega-Beltran, A.; Moral, J.; Puckett, R.D.; Morgan, D.P.; Cotty, P.J.; Michailides, T.J. Fungal communities associated with almond throughout crop development: Implications for aflatoxin biocontrol management in California. PLoS ONE 2018, 13, e0199127. [CrossRef]

20. Picot, A.; Doster, M.; Islam, M.-S.; Callicott, K.; Ortega-Beltran, A.; Cotty, P.; Michailides, T. Distribution and incidence of atoxigenic Aspergillus flavus VCG in tree crop orchards in California: A strategy for identifying potential antagonists, the example of almonds. Int. J. Food Microbiol. 2018, 265, 55-64. [CrossRef]

21. Pigłowski, M. Food hazards on the European Union market: The data analysis of the Rapid Alert System for Food and Feed. Food Sci. Nutr. 2020, 8, 1603-1627. [CrossRef]

22. Pigłowski, M. Comparative analysis of notifications regarding mycotoxins in the Rapid Alert System for Food and Feed (RASFF). Qual. Assur. Saf. Crops Foods 2019, 8, 725-735. [CrossRef]

23. Van der Fels-Klerx, H.J.I.; Adamse, P.; Punt, A.; van Asselt, E.D. Data Analyses and Modelling for Risk Based Monitoring of Mycotoxins in Animal Feed. Toxins 2018, 10, 54. [CrossRef] 
24. Kowalska, A.; Manning, L. Using the rapid alert system for food and feed: Potential benefits and problems on data interpretation. Crit. Rev. Food Sci. Nutr. 2020, 1-14. [CrossRef] [PubMed]

25. Lüth, S.; Boone, I.; Kleta, S.; Al Dahouk, S. Analysis of RASFF notifications on food products contaminated with Listeria monocytogenes reveals options for improvement in the rapid alert system for food and feed. Food Control 2019, 96, 479-487. [CrossRef]

26. Taylor, G.; Petróczi, A.; Nepusz, T.; Naughton, D.P. The Procrustean bed of EU food safety notifications via the Rapid Alert System for Food and Feed: Does one size fit all? Food Chem. Toxicol. Int. J. Publ. Br. Ind. Biol. Res. Assoc. 2013, 56, 411-418. [CrossRef] [PubMed]

27. European Commission, Directorate-General for Health and Food Safety, Health and Food Audits and Analysis. Final Report of an Audit Carried Out in the United States from 07 to 15 October 2019 in Order to Assess the Control System in Place to Control Aflatoxin Contamination in Peanuts Intended for Export to the European Union; European Commission: Brussels, Belgium, 2019.

28. European Commission, Directorate-General for Health and Food Safety, Health and Food Audits and Analysis. Final Report of an Audit Carried Out in the United States from 05 September to 12 September 2017 in Order to Assess the Control System in Place to Control Aflatoxin Contamination in Pistachios Intended for Export to the European Union; European Commission: Brussels, Belgium, 2017.

29. Alshannaq, A.F.; Gibbons, J.G.; Lee, M.-K.; Han, K.-H.; Hong, S.-B.; Yu, J.-H. Controlling aflatoxin contamination and propagation of Aspergillus flavus by a soy-fermenting Aspergillus oryzae strain. Sci. Rep. 2018, 8, 16871. [CrossRef] [PubMed]

30. Commission of the European Communities. Commission Regulation (EC) No 1881/2006 of 19 December 2006 setting maximum levels for certain contaminants in foodstuffs. Off. J. Eur. Union 2006, L364, 5-24.

31. European Commission, Directorate-General for Health And Food Safety, Health and Food Audits and Analysis. RASFF The Rapid Alert System for Food and Feed-Annual Report 2019; European Commission: Brussels, Belgium, 2019. 